\title{
CARACTERIZAÇÃO DO AMIDO DE GRÃO-DE-BICO (Cicer arietinum L.)
}

\author{
TALITA MOREIRA DE OLIVEIRA* \\ MÔNICA RIBEIRO PIROZI** \\ JOÃO TOMAZ DA SILVA BORGES*** \\ ROGÉRIO GERMANI*** \\ MAURÍCIO PAULO FERREIRA FONTES ${ }^{* * * *}$
}

\begin{abstract}
O objetivo deste trabalho foi extrair e caracterizar o amido de grão-de-bico quanto a sua composição química, estrutural e morfológica, propriedades térmicas e tecnológicas. O rendimento apresentado no processo de extração foi de $28 \%$, com alta pureza. A observação em microscopia eletrônica de varredura mostrou grânulos de amido com formato cilíndrico e oval, com dimensões de $20 \mu \mathrm{m}$ de comprimento e $10 \mu \mathrm{m}$ de largura. O padrão de cristalinidade mostrado por difratometria de raios $X$ foi do tipo $C$, típico de leguminosas. A análise das propriedades de pasta foi efetuada por calorimetria diferencial de varredura (DSC) e analisador rápido de viscosidade (RVA). Em DSC, foi encontrada a temperatura inicial de gelatinização de $65,51^{\circ} \mathrm{C}$, a final de $86,90^{\circ} \mathrm{C}$ e a entalpia de gelatinização de $12,12 \mathrm{~J} / \mathrm{g}$. O RVA mostrou temperatura inicial de gelatinização de $73,1^{\circ} \mathrm{C}$, valores elevados de viscosidade, baixa quebra e alta tendência à retrogradação. O amido apresentou pouco inchamento e solubilidade, mesmo na temperatura de $90^{\circ} \mathrm{C}$. O gel de amido de grão-de-bico mostrouse turvo e com alta sinérese e apresentou elevada dureza e elasticidade em análise de perfil de textura.
\end{abstract}

PALAVRAS-CHAVE: GRÃO-DE-BICO; AMIDO; Cicer arietinum L.

* Mestre em Ciência e Tecnologia de Alimentos, Departamento de Tecnologia de Alimentos (DTA), Universidade Federal de Viçosa (UFV), Viçosa, MG (e-mail: moreiratalita@yahoo.com.br).

** Ph.D. em Ciência de Grãos, Professora do DTA/UFV, Viçosa, MG (e-mail: mpirozi@ufv.br).

*** Doutorando em Ciência e Tecnologia de Alimentos, DTA/UFV, Viçosa, MG (e-mail: jtsborges@yahoo.com.br).

**** Doutor em Ciência de Cereais, Pesquisador do Centro Nacional de Pesquisa de Tecnologia Agroindustrial de Alimentos (EMBRAPA Agroindústria de Alimentos) - Rio de Janeiro, RJ (e-mail: germani@ctaa.embrapa.br).

*****Doutor em Ciência do Solo, Professor do DPS/UFV, Viçosa, MG (e-mail: mpfontes@ufv.br). 


\section{INTRODUÇÃO}

As leguminosas são ricas em proteínas e amido, sendo que o amido representa de $45 \%$ a $65 \%$ da sua composição. O grão-de-bico, também conhecido como garbanzo na América Latina, é cultivado principalmente na Ásia e região mediterrânea. Trata-se da terceira leguminosa mais consumida no mundo (HUANG, 2006).

Vários estudos são encontrados na literatura sobre amido de cereais e tubérculos mais disponíveis e com ampla aplicação na indústria em geral. Pesquisas sobre amido de leguminosas são mais escassas, pela dificuldade de serem encontradas em alguns países (HOOVER e RATNAYAKE, 2002).

Amidos de leguminosas são conhecidos pela alta viscosidade de gel, resistência ao inchamento e à ruptura, além do alto conteúdo de amilose. Informações com detalhes de sua estrutura e características tecnológicas são escassas (AGGARWAL et al., 2004; AGUNBIADE e LONGE, 1999), principalmente de variedades produzidas no Brasil. O grão-de-bico é cultivado principalmente na região sul do Brasil por se adaptar melhor em regiões frias (RURAL NEWS, 2005), mas o seu consumo ainda é muito limitado quando comparado com outras leguminosas como o feijão (FERREIRA, BRAZACA e ARTHUR, 2006). Seu consumo está voltado para os grãos inteiros, mas apresenta grande potencial a ser explorado nutricional e tecnologicamente, principalmente no estudo de seu amido para que novas utilizações sejam possíveis. Explorar novas fontes de amido e melhorar suas propriedades funcionais visando aproveitamento na indústria torna-se economicamente importante.

O objetivo deste trabalho foi extrair e caracterizar o amido de grão-de-bico quanto a sua composição química, estrutural e morfológica, propriedades térmicas e tecnológicas.

\section{MATERIAL E MÉTODOS}

\subsection{MATERIAL}

O grão-de-bico tipo "kabuli" foi adquirido em comércio da cidade de Viçosa (MG) em saco de $50 \mathrm{~kg}$. Após etapa preliminar de limpeza efetuou-se a seleção manual e dividiu-se o material em lotes iguais para o processamento em três dias seguidos, representando três repetições.

\subsection{EXTRAÇÃO DO AMIDO DE GRÃO-DE-BICO}

A extração do amido foi realizada segundo SINGH, SANDHU e KAUR (2004), com modificações, na planta piloto de processamento de frutas e hortaliças do Departamento de Tecnologia de Alimentos (DTA) da Universidade Federal de Viçosa (UFV).

O grão-de-bico foi lavado e mantido em solução contendo $0,2 \%$ de bissulfito de sódio durante 12 horas em temperatura ambiente. $O$ bissulfito tem a finalidade de evitar o crescimento microbiano, facilitar a entrada de água nos grãos e promover a separação da proteína aderida aos grânulos de amido. Após a drenagem da solução, os grãos foram moídos em triturador industrial (Incal - modelo 67B) na presença de água. A massa resultante foi filtrada e lavada até a retirada do máximo de amido do bagaço. Após decantação, em tanques de aço inoxidável, por período de 1 hora, o sobrenadante foi drenado, o amido separado e ressuspenso em água na mesma proporção por três vezes para a garantir maior pureza ao amido. Depois de seco em estufa a $50^{\circ} \mathrm{C}$ por 12 horas, o amido foi moído em moinho de facas e armazenado em sacos de polipropileno sob temperatura ambiente.

\subsection{COMPOSIÇÃO CENTESIMAL DO AMIDO}

As análises para determinação da composição centesimal do amido foram realizadas no laboratório de Análises Físico-Químicas do DTA/UFV. Determinou-se o teor de umidade em estufa a 
$105^{\circ} \mathrm{C}$ conforme método 925.10 da AOAC (1984) e o de lipídios após extração com éter de petróleo em extrator Soxhlet (método 920.85 da AOAC, 1984). O teor de proteínas foi determinado pelo método de Micro-Kdjedahl, empregando-se o fator 6,25 para a conversão do nitrogênio em proteína bruta (método 960.52 da AOAC, 1984). Determinou-se a quantidade de cinzas após incineração do material em mufla a $550^{\circ} \mathrm{C}$ pelo método 923.03 da AOAC (1984). O teor de fibra bruta foi determinado na amostra dessecada e desengordurada mediante digestão ácida com $\mathrm{H}_{2} \mathrm{SO}_{4} 1,25 \%$, seguida de digestão alcalina com $\mathrm{NaOH} 1,25 \%$. Após as digestões, o resíduo foi submetido a aquecimento a $105-110^{\circ} \mathrm{C}$ e pesado até massa constante (AOAC, 1996). Calculou-se o teor de carboidrato por diferença. Todas as análises foram realizadas em triplicata. Empregou-se a metodologia de determinação de amido por Digestão Ácida em Micro-ondas, descrita por CEREDA, DAIUTO e VILPOUX (2004).

\subsection{OBSERVAÇÃO DOS GRÂNULOS DO AMIDO POR MICROSCOPIA ELETRÔNICA DE VARREDURA}

A observação da morfologia dos grânulos de amido ocorreu em microscópio eletrônico de varredura Marca LEO, modelo 1430VP (Carl Zeiss, Brasil), no Núcleo de Microscopia e Microanálise da UFV. A amostra em pó foi colocada sobre superfície de alumínio e coberta com ouro com a ajuda de fita adesiva dupla face. Utilizou-se potencial de aceleração de $15 \mathrm{kV}$ e o tamanho dos grânulos foi determinado pela escala de medida da fotografia eletrônica (LEONEL, 2007; VIGNEAU, et al. 2000).

\subsection{ANÁLISE DE PROPRIEDADES DE PASTA DO AMIDO EM CALORIMETRIA DIFERENCIAL DE VARREDURA(DSC)}

Realizou-se análise de DSC no CTAA/EMBRAPA, segundo metodologia descrita por CARVALHO e MITCHELL (2001), em equipamento DSC Q200 (TA Instruments, New Castle, USA). Aproximadamente $5 \mathrm{mg}$ de amostra foram colocados em recipiente de alumínio com $10 \mathrm{mg}$ de água, usando-se recipiente vazio como referência. As análises foram realizadas com taxa de aquecimento de $10^{\circ} \mathrm{C} / \mathrm{min}$ entre 5 e $110^{\circ} \mathrm{C}$. Com base no termograma de cada ensaio no calorímetro obtiveram-se os valores de To (temperatura de início de gelatinização), Tc (temperatura final de gelatinização), Tp (temperatura de pico), $\Delta \mathrm{H}$ gel (entalpia de gelatinização) e $\mathrm{R}$ (faixa de gelatinização Tc-To).

\subsection{DETERMINAÇÃO DO PADRÃO DE CRISTALINIDADE DO AMIDO POR DIFRATOMETRIADE RAIOX}

Adotou-se a metodologia de OLIVEIRA et al. (2004), modificada conforme segue, em equipamento Rigaku Geiger-Flex (Rigaku Corporation, Tokyo, Japan) com radiação de cobalto a $40 \mathrm{KV}, 30 \mathrm{~mA}$, velocidade de varredura de $1 \%$ seg sob ângulo $2 \theta$ variando de 4 a $45^{\circ}$. Foram analisados o amido em pó e géis de amido na concentração de $8 \%$, preparados no mesmo dia da análise e com 5 dias de armazenamento na temperatura de $4^{\circ} \mathrm{C}$. Os espaçamentos "d" foram obtidos a partir da equação de Bragg ( $n \lambda=2 d \operatorname{sen} \theta)$, sendo $n=1$ e $\lambda=1,79026 \AA$.

\subsection{PODER DE INCHAMENTO (PI) E ÍNDICE DE SOLUBILIDADE (IS) DO AMIDO}

O PI e IS foram determinados conforme a metodologia de LEACH, MCCOWEN e SCHOCH (1959). Em tubos de centrífuga, previamente tarados, foram colocados aproximadamente $8 \mathrm{~g}$ de amido (Pa) e $100 \mathrm{~mL}$ de água destilada. Os tubos com a suspensão foram deixados em temperatura constante de $25,50,60,70,80$ e $90^{\circ} \mathrm{C}$ por 30 minutos, com agitação a cada 5 minutos. Em seguida, os tubos foram centrifugados a $3000 \mathrm{rpm}$ por 10 minutos. O sobrenadante foi separado, seu volume foi medido (V) e uma alíquota de $10 \mathrm{~mL}$ retirada e colocada em placa de Petri previamente tarada. Secou-se a 
placa em estufa por 3 horas a $105^{\circ} \mathrm{C}$ e calculou-se o resíduo por diferença de peso (R). O centrifugado (C) foi pesado. O poder de inchamento (PI) e o índice de solubilidade (IS) foram calculados de acordo com as equações (a) e (b):

$$
\mathrm{PI}(\mathrm{g} / \mathrm{g})=\frac{\mathrm{C}}{\mathrm{Pa}} \quad \text { (a) } \quad \mathrm{IS}(\%)=\frac{10 \times \mathrm{V} \times \mathrm{R}}{\mathrm{Pa}} \quad \text { (b) }
$$

\subsection{ANÁLISE DE PROPRIEDADES DE PASTADO AMIDO EM ANALISADOR RÁPIDO DE VISCOSIDADE (RVA)}

A determinação das propriedades de pasta ocorreu em equipamento RVA (Newport Scientific), no CTAA/EMBRAPA, segundo a metodologia de DINIZ (2006). A amostra, na concentração de $10 \%$, foi submetida à temperatura de $50^{\circ} \mathrm{C}$ por 1 minuto e depois aquecida até $95^{\circ} \mathrm{C}$ numa taxa de $6^{\circ} \mathrm{C} / \mathrm{min}$, permanecendo nessa temperatura por 5 minutos. Em seguida, resfriou-se a amostra até $50^{\circ} \mathrm{C}$ numa taxa de $6^{\circ} \mathrm{C} / \mathrm{min}$. Nessa análise foram obtidos os valores de temperatura de pasta, viscosidades máxima, mínima e final, quebra de viscosidade (diferença entre a viscosidade máxima e mínima) e tendência à retrogradação (diferença entre a viscosidade final e mínima).

\subsection{CARACTERIZAÇÃO DO GEL DE AMIDO}

Suspensão contendo $8 \%$ de amido em água foi aquecida até obtenção de gel translúcido e esse distribuído em recipientes de $100 \mathrm{~mL}$. Após resfriamento, os recipientes foram armazenados à temperatura de $4^{\circ} \mathrm{C}$. Medidas da turbidez do gel foram realizadas utilizando-se análise da absorvância a $640 \mathrm{~nm}$ em espectrofotômetro (GBC UV/VIS 918) no mesmo dia do preparo do gel (to) e a cada 24 horas, totalizando 4 dias ( $\mathrm{t} 1, \mathrm{t} 2, \mathrm{t} 3, \mathrm{t} 4)$. Para a análise de sinérese mediu-se a porcentagem de água liberada dos géis em relação ao peso total, após centrifugação a $3000 \mathrm{rpm}$ por 15 minutos durante os 4 dias da análise ( $11, \mathrm{t} 2, \mathrm{t} 3, \mathrm{t} 4)$. Amostras de géis foram também congeladas na temperatura de $-15^{\circ} \mathrm{C}$ para determinação da porcentagem de água liberada após 5 ciclos de congelamento/ descongelamento (DINIZ, 2006; SINGH, SANDHU e KAUR, 2004).

Análises do perfil de textura do gel de amido $8 \%$ foram realizadas em Aparelho Universal de Teste Instron, modelo 3367, mediante curva de força $x$ tempo (CHOI e KERR, 2003). Os géis foram colocados em béqueres de $60 \mathrm{~mm}$ de diâmetro e $40 \mathrm{~mm}$ de altura e deixados em temperatura ambiente durante $24 \mathrm{~h}$. Após esse tempo, as amostras foram submetidas às análises realizadas com sete corpos de prova. Utilizou-se probe cilíndrico de $10 \mathrm{~mm}$ de diâmetro (P-25R) e plataforma HDP/ 90, com velocidade pré-teste, de teste e pós-teste de $1,0 \mathrm{~mm} / \mathrm{s}$ e penetração de $40 \%$. Os géis foram comprimidos duas vezes, obtendo-se a curva do perfil de textura e as propriedades de dureza $(\mathrm{N})$, adesividade $(\mathrm{J})$, mastigabilidade $(\mathrm{N})$, coesividade, gomosidade e elasticidade $(\mathrm{mm})$ foram avaliados.

\section{RESULTADOS E DISCUSSÃO}

\subsection{EXTRAÇÃO DO AMIDO DE GRÃO-DE-BICO}

O procedimento de extração mostrou-se simples, com rápida decantação do amido. Após a secagem, o amido apresentou cor branca e sem impurezas aparentes.

Obteve-se rendimento de $28 \%$ b.s., superior a outras fontes amiláceas como mandioquinha salsa (10,3\% - MATSUGUMA, 2006), biri (11,44\% - LEONEL et al., 2002), mandioca (22-27\% CEREDA et al., 2002) e banana (5-8\% - FREITAS e TAVARES, 2005), mas inferior ao de lentilha 
(32,7 a 33,7\% - RATNAYAKE et al., 2001). SINGH, SANDHU e KAUR (2004) também obtiveram valores elevados de rendimento, entre 29 a 35,2\%, para diferentes variedades de grão-de-bico. As diferenças podem ser decorrentes da variedade, maturação e procedimentos de extração.

\subsection{COMPOSIÇÃO CENTESIMAL DO AMIDO DE GRÃO-DE-BICO}

Os valores encontrados para a composição centesimal do amido de grão-de-bico (Tabela 1) estão de acordo com a Resolução CNNPA n 12 - 1978 para amidos comerciais, que permite 14\% de umidade, $0,5 \%$ de cinzas no máximo e $80 \%$ de amido no mínimo (SÃO PAULO, 1978).

$\mathrm{O}$ amido de grão-de-bico apresentou baixo conteúdo de lipídios e proteínas. O teor de lipídio pode ser considerado baixo (menor que 1\%) de acordo com MOORTHY (2001). A pureza obtida pelo procedimento de extração foi confirmada, principalmente devido ao baixo teor de cinzas e fibras. Segundo VILPOUX e CEREDA (1995) são aceitáveis valores de fibras abaixo de 0,59\% para evitar que se restrinja o uso do amido em algumas aplicações.

A pureza dos amidos está relacionada com sua composição química, sendo desejável baixos teores de lipídios e cinzas e ausência de proteína aderida aos grânulos. Os lipídios representam fração muito importante associada com o grânulo, sendo responsáveis pela fixação de cor, desenvolvimento de aromas e complexações (BULÉON et al, 1998).

\section{TABELA 1 - COMPOSIÇÃO QUÍMICA DO AMIDO DE GRÃO-DE-BICO}

\begin{tabular}{lc}
\hline \multicolumn{1}{c}{ Composição } & $\%$ \\
\hline Carboidratos totais & 90,30 \\
Umidade & 7,85 \\
Proteínas & 1,26 \\
Lipídios & 0,52 \\
Fibra bruta & $\mathrm{nd}^{*}$ \\
Cinzas & 0,07 \\
\hline
\end{tabular}

*não detectável.

O teor de amido obtido mostrou-se elevado (95,82\% em relação ao total de carboidratos), comprovando mais uma vez a pureza da extração.

SINGH, SANDHU e KAUR (2004) obtiveram valores de cinzas que variaram de 0,03-0,08\%; 0,04-0,09\% de lipídios; 0,69-0,89\% de proteína e 28,6-34,3\% de amilose em estudo com diversas variedades de grão-de-bico. HUANG et al. (2007a) encontraram $11,9 \%$ de umidade, $94 \%$ de amido, $27,2 \%$ de amilose, $0,57 \%$ de proteína e $0,10 \%$ de lipídios.

\subsection{CARACTERIZAÇÃO DO AMIDO DE GRÃO-DE-BICO}

\subsubsection{Formato e tamanho dos grânulos}

A análise em microscópio eletrônico de varredura mostrou grânulos com formato cilíndrico e oval, alguns alongados. Observou-se estrutura lisa, sem fissuras, o que demonstra grânulos íntegros e não danificados (Figura 1). As dimensões médias dos grânulos foram de $20 \mu \mathrm{m}$ de comprimento e $10 \mu \mathrm{m}$ de largura, coerentes com os valores observados por SINGH, SANDHU e KAUR (2004). Tais valores são aproximados pela dificuldade de se medir o tamanho de grânulo de amido por microscopia devido sua irregularidade e diversidade de formas (CEREDA et al., 2002). 


\section{FIGURA 1 - MICROSCOPIA ELETRÔNICA DOS GRÂNULOS DE AMIDO DE GRÃO-DE-BICO}

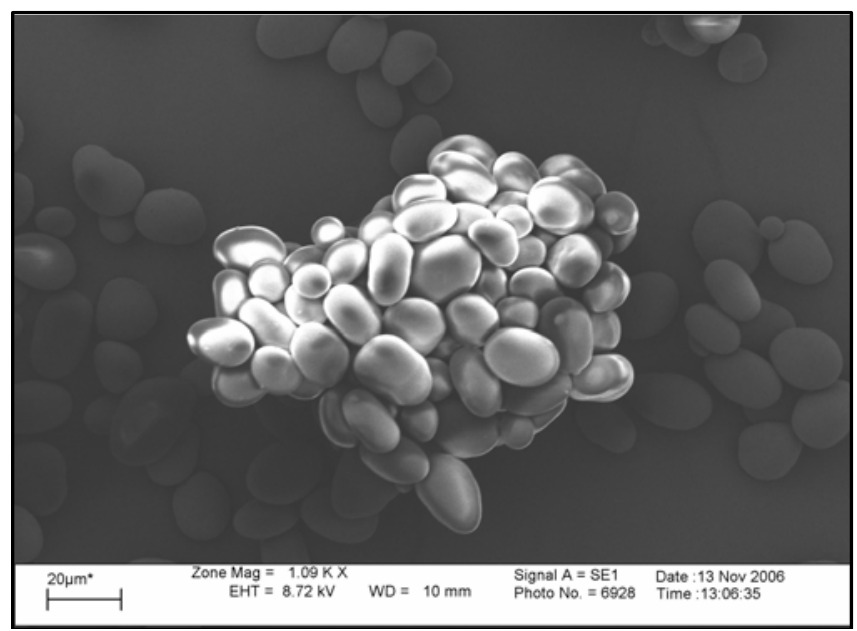

CEREDA et al. (2002) encontraram na literatura os menores grânulos de amido em taioba e cará (2 a $5 \mu \mathrm{m})$ e os maiores em biri e inhame $(25$ a $50 \mu \mathrm{m})$. Os valores obtidos ficaram próximos aos de outras leguminosas, como feijão (11,8 a 26,7 $\mu \mathrm{m})$ (SALGADO et al., 2005) e lentilha (10 a $25 \mu \mathrm{m})$ (RATNAYABE et al., 2001).

\subsubsection{Análise de propriedades de pasta do amido em Calorimetria Diferencial de Varredura (DSC)}

A análise do termograma obtido neste estudo para o amido de grão de bico (Figura 2) revelou temperatura inicial $\left(\mathrm{To}-65,5^{\circ} \mathrm{C}\right)$, temperatura de pico $\left(\mathrm{Tp}-70,90^{\circ} \mathrm{C}\right)$ e temperatura final $\left(\mathrm{Tc}-86,90^{\circ} \mathrm{C}\right)$ superiores àquelas relatadas por SINGH, SANDHU e KAUR $(2004)$ de $61,5-64,8^{\circ} \mathrm{C}, 66,4-69^{\circ} \mathrm{C}$ e $71,3-$ $73,8^{\circ} \mathrm{C}$, respectivamente. KÖKSEL et al. (1998) encontraram os valores de $\mathrm{To}=65,7^{\circ} \mathrm{C} ; \mathrm{Tp}=70,5^{\circ} \mathrm{C} \mathrm{e}$ HUANG et al. $(2007 \mathrm{a})$ de $\mathrm{To}=57,9^{\circ} \mathrm{C}, \mathrm{Tp}=63,5^{\circ} \mathrm{C}$ e Tc $=70,4^{\circ} \mathrm{C}$. Essas diferenças podem ser atribuídas ao processo de cultivo e às características de cada planta, possivelmente pelas variações no conteúdo de amilose, de tamanho, forma e distribuição dos grânulos de amido e ao arranjo interno de frações.

\section{FIGURA 2 - ANÁLISE DO TERMOGRAMA OBTIDO EM DSC PARA O AMIDO DE GRÃO-DE-BICO}

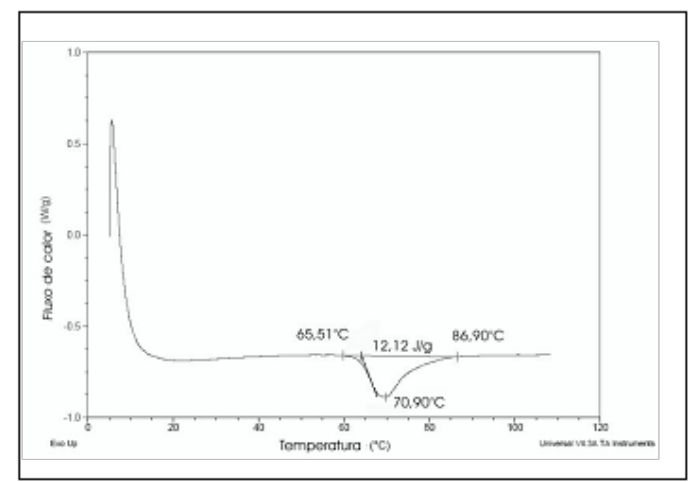

$\mathrm{T}_{0}=65,51^{\circ} \mathrm{C}$ (temperatura inicial), $\mathrm{Tp}=70,90^{\circ} \mathrm{C}$ (temperatura de pico) $, T c=86,90^{\circ} \mathrm{C}$ (temperatura final), ?H gel $=12,12 \mathrm{~J} / \mathrm{g}$ (entalpia de gelatinizaçã̃o), $R=21,39$ (faixa de gelatinizaçã̃ $0=T c-T_{0}$ ).

$\mathrm{To}=65,51^{\circ} \mathrm{C}$ (temperatura inicial), $\mathrm{Tp}=70,90^{\circ} \mathrm{C}$ (temperatura de pico), $\mathrm{Tc}=86,90^{\circ} \mathrm{C}$ (temperatura final), $\triangle \mathrm{H}$ gel $=12,12$ $\mathrm{J} / \mathrm{g}$ (entalpia de gelatinização), $\mathrm{R}=21,39$ (faixa de gelatinização= Tc-To). 
A depressão mostrada no termograma da Figura 2 representa a reação endotérmica de gelatinização, que envolve a fusão dos grânulos. De acordo com NODA et al., citados por SINGH, SANDHU e KAUR (2004), To, Tp e Tc são influenciados pela estrutura molecular da região cristalina, que corresponde à distribuição das cadeias curtas de amilopectina. A entalpia de gelatinização ( $\triangle \mathrm{Hgel})$ pode ser correlacionada à cristalinidade da amilopectina e à força com que as duplas hélices formadas por suas cadeias estão associadas no grânulo. Assim, quanto maior o $\Delta \mathrm{H}$, maior a força necessária para o rompimento da estrutura dos grânulos, que resulta em gelatinização. Esses últimos autores consideraram entalpia de $8,7 \mathrm{~J} / \mathrm{g}$ alta para amido de grão-de-bico, indicando que a associação da amilopectina foi muito forte no material estudado $(12,12 \mathrm{~J} / \mathrm{g})$.

Alto valor para a faixa de gelatinização $(R)$ foi observado para o amido de grão-de-bico, sugerindo a presença de cristais com estabilidade diferenciada dentro da zona cristalina (SINGH, SANDHU e KAUR, 2004), que são rompidos em diferentes temperaturas.

\subsubsection{Determinação do padrão de cristalinidade do amido por difratometria de Raio $X$}

O padrão de cristalinidade mostrado pelo amido de grão-de-bico (Figura 3) evidenciou picos de maior intensidade em 17,55; 19,90 e 27,05. De acordo com CEREDA et al. (2002), o padrão do tipo A apresenta picos de maior intensidade em $2 \theta$ de 15, 17, 18 e 23 e o tipo B em 5,6; 15, 17, 22 e 23 (Figura 4). O pico em torno de 5,54 é indicativo do padrão B (HOOVER e RATNAYAKE, 2002) e mais no final do gráfico do padrão $A$. $O$ padrão tipo $A$, termodinamicamente mais estável e mais denso do que o padrão B, indica maior coesividade entre as moléculas (TEIXEIRA et al., 1998). O tipo C apresentase como padrão intermediário entre os dois. Com isso, pode-se afirmar que o amido de grão-de-bico segue o padrão de cristalinidade do tipo $C$, comum para leguminosas. Outros autores também reportam padrão de cristalinidade tipo C para o grão-de-bico (HUANG et al. 2007a e SINGH, SANDHU e KAUR, 2004). KÖKSEL et al. (1998) reportaram padrão de difração do tipo $C$ para o amido de grão-de-bico, com picos correspondentes ao ângulo $2 \theta$ entre $14-16^{\circ}, 16-17,5^{\circ}, 17,5-19^{\circ}$ e $21,5-25^{\circ}$. Também são designados subpadrões $\mathrm{Ca}$ e $\mathrm{Cb}$ dependendo da proximidade do padrão $\mathrm{C}$ com os tipos $\mathrm{A}$ e B. Pelo gráfico obtido, o amido de grão-de-bico assemelhou-se mais com o tipo A. SALGADO et al. (2005) e RATNAYAKE et. al (2001) analisando amido de feijão e lentilha, respectivamente, também constataram padrões tipo $C$, típicos das leguminosas. Segundo esses autores, o amido de leguminosas contém características do tipo A e B em proporções variadas.

Os difratogramas obtidos para os géis de amido (Figura 3) não demonstraram nenhum padrão de cristalinidade. Isso indica que a reassociação das moléculas durante a retrogradação não ocorreu de forma organizada e cristalina. Segundo JENKINS e DONALD (1998), durante o processo de gelatinização ocorre o inchamento dos grânulos e consequentemente a perda de cristalinidade.

\section{FIGURA 3 - DIFRATOGRAMA DE RAIOS X DO AMIDO DE GRÃO-DE-BICO NATIVO (a) E DO GEL COM 5 DIAS DE ARMAZENAMENTO (b)}
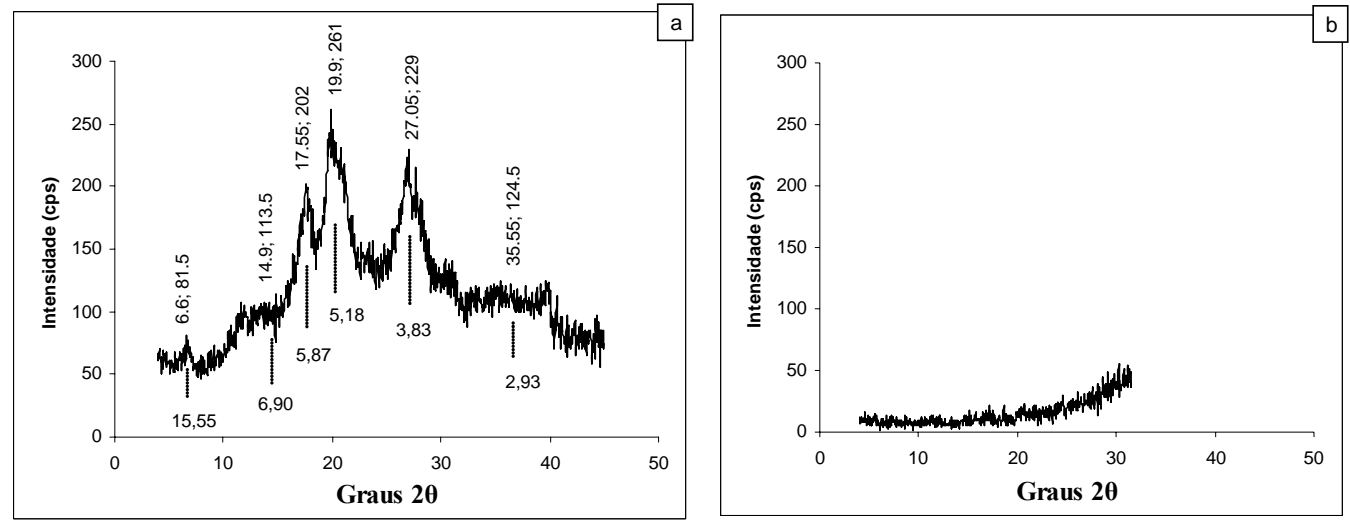

NOTA: as linhas tracejadas abaixo dos picos indicam os valores de espaçamento "d" em Angstron. 


\section{FIGURA 4 - PADRÕES DE DIFRAÇÃO DO TIPO A E B}

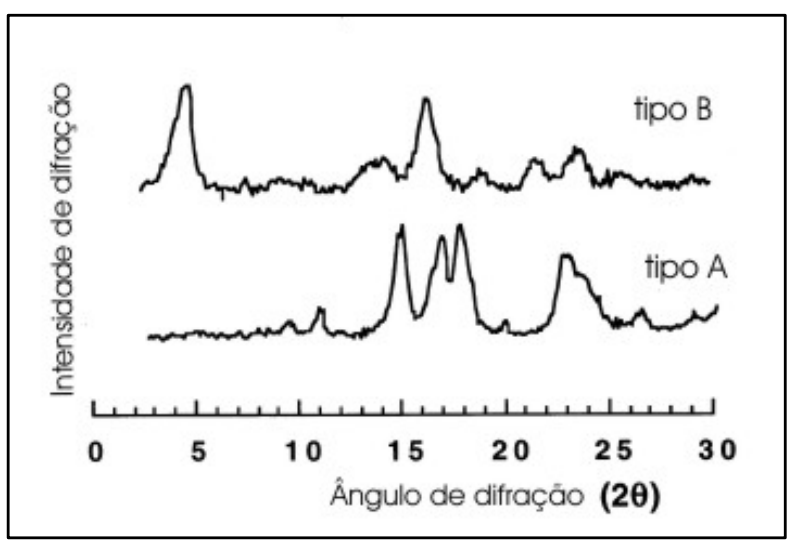

Fonte: BULÉON et al. (1998).

\subsection{PROPRIEDADES TECNOLÓGICAS DO AMIDO DE GRÃO-DE-BICO}

\subsubsection{Poder de Inchamento (PI) e Índice de Solubilidade (IS)}

$\mathrm{O}$ amido não mostrou grande variação no $\mathrm{PI}$ e IS até $60^{\circ} \mathrm{C}$, porém acima dessa temperatura as alterações foram grandes (Figura 5), indicando ruptura das ligações internas do grânulo. Esse comportamento não surpreende, uma vez que a temperatura inicial de gelatinização observada no DSC foi também superior a $60^{\circ} \mathrm{C}$. Tanto o PI quanto o IS dependem do arranjo das moléculas de amilose e amilopectina nos grânulos de amido, e por isso os dois índices mostram comportamento similar. A força do arranjo micelar controla o comportamento do amido em água (AMANTE 1986). $O$ aumento da temperatura provoca rompimento de ligações intermoleculares e a abertura das cadeias permite a entrada de moléculas de água (AGUNBIADE e LONG, 1999).

$\mathrm{Na}$ temperatura de $90^{\circ} \mathrm{C}$, o amido de grão-de-bico apresentou valores de $\mathrm{PI}$ de $8,62 \mathrm{~g} / \mathrm{g}$ e IS de $6,74 \%$. SINGH, SANDHU e KAUR (2004) encontraram valores para PI de 11,4-13,6 g/g e IS de 13,2$14,9 \%$ para diferentes variedades de amido de grão-de-bico. PERONI (2003), que estudou várias fontes de amido, encontrou os mais baixos valores de PI e IS para amido de gengibre $(9,06 \mathrm{~g} / \mathrm{g} \mathrm{e} 2,13 \%$ a

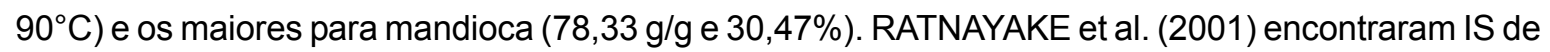
$27,2 \%$ para amido de lentilha a $95^{\circ} \mathrm{C}$. A comparação desses dados indica que o amido de grão-de-bico apresenta inchamento limitado, ou seja, baixa absorção de água e baixa solubilidade.

\section{FIGURA 5 - PODER DE INCHAMENTO (PI) E ÍNDICE DE SOLUBILIDADE (IS)} DO AMIDO DE GRÃO-DE-BICO

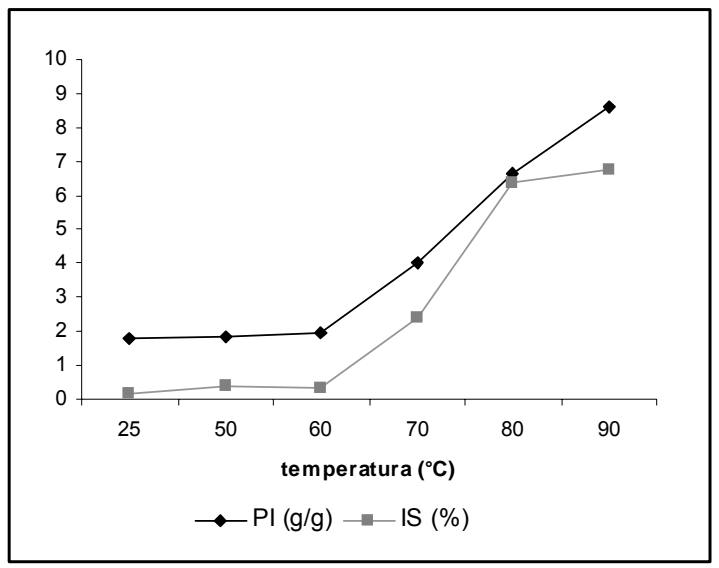


O inchamento do grânulo ocorre simultaneamente com a perda de birrefringência e precede a solubilização. O PI geralmente é influenciado pela força de ligação entre as moléculas e pela estrutura molecular da amilopectina. Baixo PI pode ser atribuído à presença de vários cristais formados pela associação de longas cadeias de amilopectina. Maior cristalinidade implica em maior estabilidade granular o que consequentemente reduz a capacidade de inchamento do grânulo (SINGH, SANDHU e KAUR, 2004). Amidos ricos em amilose mostram inchamento e solubilidade restritos, mesmo após período prolongado de aquecimento (CEREDA et al., 2002). SANDHYA, RANI e BHATTACHARYA (1989) mostraram que grânulos de amido com baixa quantidade de amilose são menos rígidos e absorvem mais água quando aquecidos.

O teor de amilose no amido de grão-de-bico varia de 28,6 a 34,3 g/100 g (SINGH, SANDHU e KAUR, 2004), sendo superior àquele registrado para a maioria das fontes tradicionais de amido como mandioca (20,4 a 25,4 g/100 g), batata (17-21,8 g/100 g), milho (15,6 a 25,8 g/100 g) e trigo (13 a $18,2 \mathrm{~g} / 100 \mathrm{~g}$ ) (CEREDA et al., 2002). Seu teor de amilose apresentou-se inferior apenas ao encontrado para a lentilha (48,8 a 49,6\%) (RATNAYAKE et al., 2001).

\subsubsection{Análise de propriedades de pasta do amido em Analisador Rápido de Viscosidade (RVA)}

A análise do resultado obtido em RVA permite observar amido resistente ao aquecimento e à agitação mecânica, sem perda acentuada de viscosidade durante o processo (Figura 6). 0 amido de grão-de-bico apresentou valores elevados de viscosidade e temperatura de pasta, pequena quebra e alta tendência à retrogradação. Esses dados mostram alto potencial para a formação de gel quando resfriado e estabilidade térmica, indicando fortes ligações no interior do grânulo e alto grau de associação entre as moléculas, que mantém a estrutura granular sob força mecânica e variações de temperatura. De acordo com PERONI (2003), a alta tendência à retrogradação é típico de amidos com alto teor de amilose pela maior facilidade dessa molécula em se reassociar com o resfriamento da pasta.

A temperatura de pasta obtida pelo RVA foi maior do que a temperatura inicial de gelificação (To) do DSC. De acordo com PERONI (2003) isso ocorre porque o DSC consegue detectar quando os primeiros grânulos começam a se desorganizar, sendo valores mais precisos. O RVA tem sensibilidade para detectar os primeiros acréscimos na viscosidade geral da pasta.

\section{FIGURA 6 - DADOS OBTIDOS NO RVA PARA O AMIDO DE GRÃO-DE-BICO}

\begin{tabular}{|l|l|c|}
\hline \multicolumn{2}{|c|}{ Parâmetros } & Valores \\
\hline Umidade & Múxima & 10,06 \\
\hline \multirow{3}{*}{ Wscosidade } & Munima & 3312,4 \\
\cline { 2 - 3 } & Final & 4702,8 \\
\hline Quebra (Shear Thinning)cP & 878,1 \\
\hline $\begin{array}{l}\text { Tendência à retrogradação (Set } \\
\text { back)cP }\end{array}$ & 2268,4 \\
\hline \multicolumn{2}{|l|}{ Temperatura inicial de pasta ( ${ }^{\circ} \mathrm{C}$ ) } & 73,1 \\
\hline
\end{tabular}

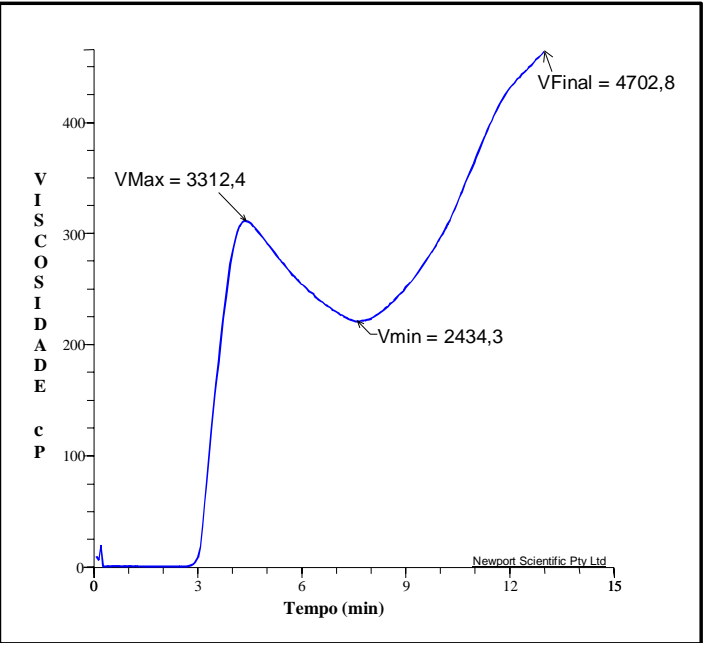


A temperatura inicial de pasta corresponde àquela em que a suspensão de amido começa a aumentar sua viscosidade. Altas temperaturas de pasta evidenciam poucas regiões amorfas dos grânulos (LEONEL et al., 2003). A viscosidade final, parâmetro importante no uso de amido em alimentos, corresponde à viscosidade a ser desenvolvida no produto final e, portanto, apreciada pelo consumidor. A viscosidade elevada durante resfriamento permite manter as propriedades de alimentos formulados durante e após o processamento térmico.

SINGH, SANDHU e KAUR (2004) obtiveram, para diferentes variedades de grão-de-bico, valores de temperatura de pasta entre $75,1-77,1^{\circ} \mathrm{C}$, viscosidade no pico de $1107-2173 \mathrm{cP}$, viscosidade final de 1639-3250 cP e tendência à retrogradação de 532-1132 cP.

No estudo de HUANG (2006) com amido de feijão caupi, grão-de-bico e ervilha, o primeiro apresentou os maiores picos de viscosidade e tendência à retrogradação bastante elevada. $\mathrm{O}$ amido de grão-de-bico apresentou comportamento intermediário e o de ervilha os menores valores de viscosidade. Os gráficos não apresentaram picos de viscosidade de pasta, a viscosidade se manteve constante durante o aquecimento e aumentou durante o resfriamento. AGUNBIADE e LONGE (1999) também estudaram amidos de leguminosas (feijão caupi - Vigna unguiculata, guandu - Cajanus cajan e feijão africano - Sphenostylis stenocarpa) e os três tipos exibiram baixa quebra e alta tendência à retrogradação, mostrando estabilidade durante o aquecimento.

\subsubsection{Caracterização do gel de amido de grão-de-bico}

\subsubsection{Turbidez}

O gel de amido de grão-de-bico apresentou absorvância de 2,99 a 640 nm, após 4 dias de armazenamento na temperatura de $4^{\circ} \mathrm{C}$ (Figura 7). Observou-se aumento da turbidez dos géis com 0 tempo de estocagem, assim como o verificado por SINGH, SANDHU e KAUR (2004). O aumento da turbidez pode estar relacionado com o rearranjo das moléculas de amilose e amilopectina, o que provoca a dispersão da luz.

\section{FIGURA 7 - ABSORVÂNCIA A 640 nm PARA O GEL DE AMIDO DE GRÃO-DE-BICO ARMAZENADO A $4^{\circ} \mathrm{C}$ DURANTE 4 DIAS}

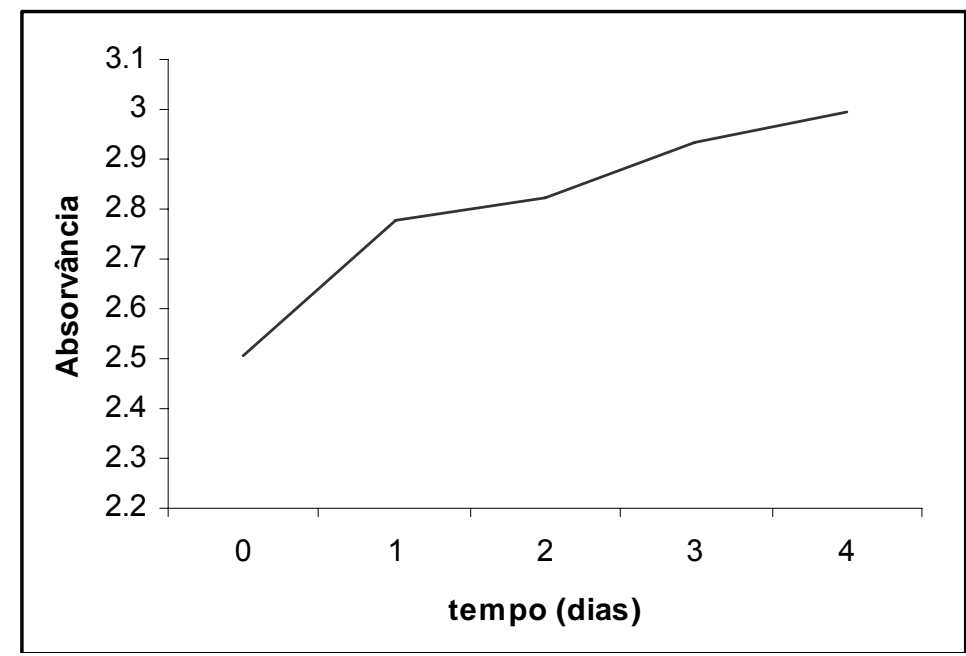

A transparência/opacidade da pasta de amido constitui atributo importante de qualidade do amido e, dependendo da aplicação no alimento, pode ser preferível um ou outro atributo. De acordo 
com CRAIG et al. (1989), a pasta opaca apresenta estrutura granular mais organizada, com maior associação entre as cadeias, o que dificulta a passagem de luz. Esses autores encontraram valores de absorvância a $650 \mathrm{~nm}$ para pastas de amido de batata de 0,036 , mandioca de 0,48 , trigo de $0,92 \mathrm{e}$ milho de 1,22. Isso indica menor transparência do gel de amido de grão-de-bico em relação a essas outras fontes, como consequência do seu maior teor de amilose. Amidos com maior teor de amilose e com alta tendência à retrogradação apresentam géis opacos e mais firmes (SILVA et al., $2006 \mathrm{e}$ MATSUGUMA, 2006), o que pode ser comprovado pelos resultados obtidos com o amido de grão-debico.

\subsubsection{Ciclo de congelamento/descongelamento}

Pode-se observar, pela Figura 8, que a perda de água do gel de amido de grão-de-bico aumenta com o tempo de estocagem, chegando a $28,35 \%$ após 5 dias. SINGH, SANDHU e KAUR (2004) reportaram sinérese de 18,5\% numa variedade de grão-de-bico contendo $34,3 \%$ de amilose após estocagem a $4^{\circ} \mathrm{C}$ por 5 dias. A sinérese ocorreu rapidamente nos três primeiros ciclos, reduzindo a taxa no ciclo seguinte e depois voltou a aumentar. Trata-se de taxa relativamente alta, que está associada à elevada reassociação molecular durante o resfriamento e estocagem, fazendo com que as moléculas de água sejam liberadas em maior quantidade.

As pastas de amido sofrem transformações estruturais por resfriamento lento ou natural, após tratamento térmico que no conjunto são relatadas como retrogradação. A retrogradação ocorre quando as moléculas de amido se reassociam e formam estrutura ordenada. Durante esse processo, há liberação de água, fenômeno denominado de sinérese (MATSUGUMA, 2006).

Os valores de sinérese do amido de grão-de-bico estão abaixo dos de lentilha encontrados por RATNAYAKE et al. (2001) de 18,6; 23; 24; 24; 25,5 para cinco ciclos de congelamento/descongelamento, com exceção do último ciclo.

\section{FIGURA 8 - PERDA DE ÁGUA DO GEL DE AMIDO DE GRÃO-DE-BICO ARMAZENADO A $4^{\circ} \mathrm{C}$ APÓS 5 CICLOS DE CONGELAMENTO E DESCONGELAMENTO}

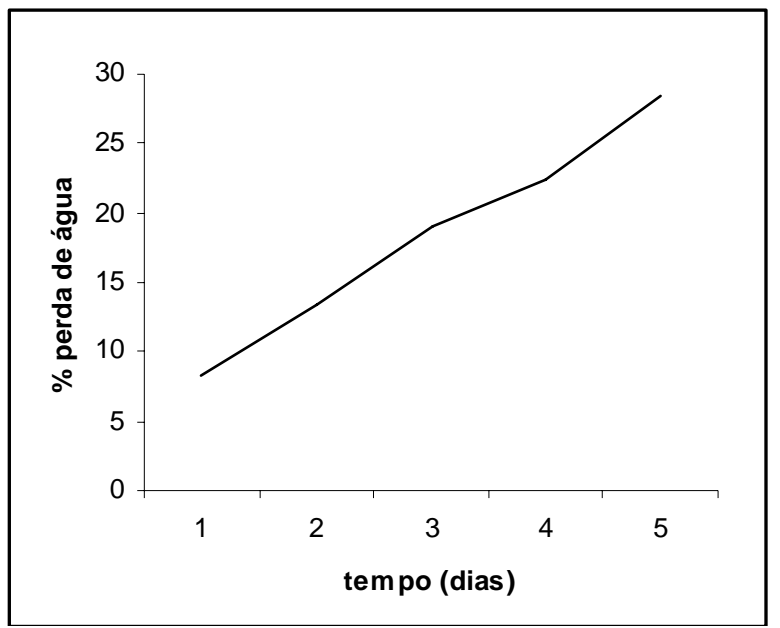

A metodologia de congelamento e descongelamento visa simular o que ocorre no ciclo da produção industrial até o consumo final. REGE e PAI (1996) comentaram que alto teor de amilose resulta em extensiva retrogradação, provocando perda de água principalmente quando os géis são submetidos a ciclos de congelamento e descongelamento e que isso pode prejudicar algumas de suas aplicações. A maior liberação de água prejudica a textura do produto, sendo características indesejáveis para molhos de alimentos, molhos de saladas e sobremesas (MATSUGUMA, 2006). 


\subsubsection{Perfil de textura do gel}

A curva e as propriedades obtidas no teste de perfil de textura estão na Figura 9 e na Tabela 2, respectivamente. A análise de perfil de textura simula a mastigação humana, sujeitando a amostra à compressão, seguida por relaxamento e nova deformação. A compressão é repetida duas vezes para gerar a curva força $x$ tempo, visando à determinação de alguns itens.

\section{FIGURA 9 - CURVA OBTIDA PELO TESTE DE TEXTURA PARA O GEL DE AMIDO DE GRÃO-DE-BICO}

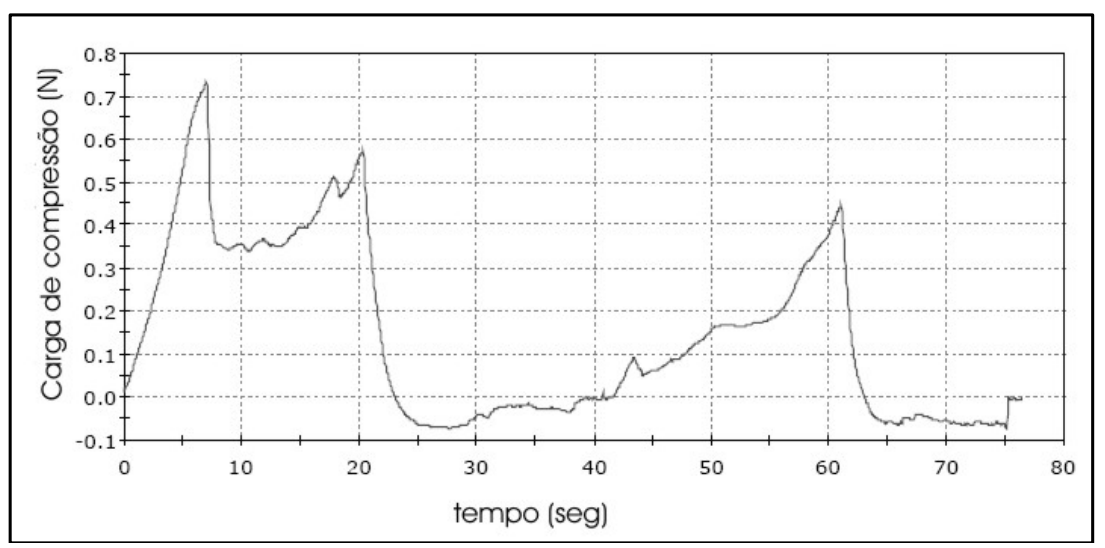

Os dados de textura variam com a concentração do gel, mas mesmo numa concentração baixa (8\%) o gel de amido de grão-de-bico apresentou consistência mais dura que o de batata na mesma concentração. Os valores mais altos foram de mastigabilidade e elasticidade, o que reflete a sua dureza e coesão entre as partículas (Tabela 2).

A dureza e a adesividade são características que dependem de forças coesivas e da viscosidade do gel, sendo inversamente proporcionais. Maior interação entre as moléculas resulta em maior resistência e dureza do gel, impedindo que as partículas se desprendam e grudem na superfície do equipamento (ou na boca). A baixa adesividade do gel de amido de grão-de-bico mostra a dificuldade de rompimento das partículas.

TABELA 2 - COMPARAÇÃO DAS PROPRIEDADES DE TEXTURA ENTRE O GEL DO AMIDO DE GRÃO-DE-BICO E DE BATATA

\begin{tabular}{lcc}
\hline \multirow{2}{*}{ Propriedades } & \multicolumn{2}{c}{ Amidos } \\
\cline { 2 - 3 } & Grão-de-bico & Batata $^{1}$ \\
\hline Dureza $(\mathrm{N})$ & 0,72 a 1,00 & 0,16 a 0,21 \\
Adesividade $(\mathrm{J})$ & $-0,0004$ a $-0,0012$ & 0,567 a 0,699 \\
Mastigabilidade $(\mathrm{N})$ & 7,01 a 24,59 & n.a. \\
Coesividade & 0,41 a 0,85 & 0,50 a 0,64 \\
Gomosidade & 0,35 a 1,22 & 0,08 a 0,14 \\
Elasticidade $(\mathrm{mm})$ & 10,65 a 17,51 & 0,88 a 0,96 \\
\hline
\end{tabular}

*Não apresentado no trabalho.

${ }^{1}$ KAUR et al. (2007).

A elasticidade constitui medida da forma como a estrutura do gel quebra dentro da boca. Alta elasticidade aparece quando o gel quebra em pedaços grandes durante a primeira compressão. Géis 
pouco elásticos se rompem mais facilmente durante a mastigação do que outro mais elástico e firme. A mastigabilidade simula a energia necessária para mastigar uma amostra semisólida até o ponto adequado para engolir (HUANG et al., 2007b).

A firmeza de géis é causada principalmente pela retrogradação do amido, atribuída à formação de associações entre as moléculas e junto com a sinérese resulta em géis mais firmes. Géis com maior rigidez geralmente apresentam maior teor de amilose e cadeias de amilopectina longas. As propriedades dos géis dependem de fatores como as características da matriz de amilose, a rigidez dos grânulos gelatinizados e a interação entre as fases dispersas e contínuas do gel (SANDHU e SINGH, 2007).

\title{
4 CONCLUSÃo
}

O amido de grão-de-bico pode ser extraído com tecnologia simples, apresentando alto rendimento e elevada pureza.

A análise do amido de grão-de-bico em calorimetria diferencial de varredura mostrou entalpia de gelatinização $(\triangle \mathrm{H})$ relativamente alta e ampla faixa de gelatinização (Tc-To), indicando alta cristalinidade da amilopectina e associação de suas cadeias laterais.

O amido de grão-de-bico nativo apresenta padrão intermediário de cristalinidade (tipo C), típico de leguminosas, porém com clara tendência ao tipo $A$ (mais cristalino).

As análises de pasta do amido de grão-de-bico mostraram resistência ao aquecimento, baixo poder de inchamento e solubilidade.

O amido de grão-de-bico apresenta boa capacidade de formação de géis, de elevada dureza e elasticidade. As análises indicaram alta interação molecular durante retrogradação. Essa interação, porém, não acontece de maneira organizada de forma a permitir a volta da configuração original responsável pela cristalinidade (característica de amido com alto teor de amilose).

As características indicam boa aplicação do amido para a utilização em filmes pela resistência da pasta em temperatura elevada e a possibilidade de formar géis firmes e resistentes, o que pode favorecer a resistência do material em temperatura ambiente.

\begin{abstract}
CHICKPEA (Cicer arietinum L.) STARCH CHARACTERIZATION

The aim of this study was to extract and characterize the starch from chickpea for its chemical, structural and morphological composition, thermal and technological properties. Chickpea starch yield was of $28 \%$, having high purity. Scanning electron micrographs revealed cylindrical and oval granules, with mean length and width of $20 \mu \mathrm{m}$ and $10 \mu \mathrm{m}$, respectively. X-ray pattern could be assigned to a C- type starch, typically of legume seeds. Pasting properties from chickpea starch were measured using differential scanning calorimetry (DSC) and rapid visco analyzer (RVA). The DSC parameters such as onset temperature, conclusion temperature and enthalpy of gelatinization were $65.51^{\circ} \mathrm{C}, 86.90^{\circ} \mathrm{C}$ and $12,12 \mathrm{~J} / \mathrm{g}$, respectively. Pasting temperature evaluated from RVA was $73.1^{\circ} \mathrm{C}$ and was observed high viscosity values and set-back and low shear thinning. Chickpea starch showed low swelling power and solubility at $90^{\circ} \mathrm{C}$. Starch gel showed high turbidity values and syneresis and, at texture profile analysis, were observed high compressive force and springiness.
\end{abstract}

KEY-WORDS: CHICKPEA; STARCH; Cicer arietinum L.

\section{REFERÊNCIAS}

1 AGGARWAL, V.; SINGH, N.; KAMBOJ, S.S.; BRAR, P.S. Some properties of seeds and starches separated from different Indian pea cultivars. Food Chemistry, v. 85, n. 4, p. 585-590, 2004.

2 AGUNBIADE, S.O.; LONGE, O.G. The physico-functional characteristics of starches from cowpea (Vigna unguiculata), pigeon pea (Cajanus cajan) and yambean (Sphenostylis stenocarpa). Food Chemistry, v. 65, n. 4, p. 469-474, 1999. 
3 AMANTE, E.R. Caracterização de amidos de variedades de mandioca (Manihot esculenta, Crantz) e de batata-doce (Ipomoea batatas). Viçosa, 1986. 109 p. Tese (Mestrado em Ciência e Tecnologia de Alimentos) - Universidade Federal de Viçosa.

4 AOAC. Association of Official Analytical Chemists. Official methods of analysis of AOAC international. Virginia, 1996.

5 AOAC. Association of Official Analytical Chemists. Official Methods of Analysis. 14 ${ }^{\text {th }}$ ed. Arlington, 1984. $1141 \mathrm{p}$.

6 BULÉON, A.; COLONNA, P.; PLANCHOT, V; BALL, S. Mini review. Starch granules: structure and biosynthesis. International Journal of Biological Macromolecules, v.23, n. 2, p. 85-112, 1998.

7 CARVALHO, C.W.P.; MITCHELL, J.R. Effect of sucrose on starch conversion and glass transition of nonexpanded maize and wheat extrudates. Cereal Chemistry, v. 78, n. 3, p. 342-348, 2001

8 CEREDA, M.P.; DAIUTO, E.R.; VILPOUX, O. Metodologia de determinação de amido por digestão ácida em microondas. Revista ABAM, v. 2, n. 8, p. 1-29, 2004.

9 CEREDA, M.P.; FRANCO, C.M. L.; DAIUTO, E.R.; DEMIATE, I.M.; CARVALHO L.J.C.B.; LEONEL, M.; VILPOUX, O.F.; SARMENTO, S. B. S. Propriedades gerais do amido. São Paulo: Fundação Cargill, 2002. 204 p. (Série Culturas de Tubérculos Amiláceas Latino Americanas, 1).

$10 \mathrm{CHOI}, \mathrm{S}$. G.; KERR, W. L. Water mobility and textural properties of native and hydroxypropylated wheat starch gels. Carbohydrate Polymers, v. 51, n. 1, p. 1-8, jan. 2003.

11 CRAIG, S.A.S.; MANINGAT, C.C.; SEIB, P.A.; HOSENEY R.C. Starch paste clarity. Cereal Chemistry, v. 66, n. 3, p. 173-182, 1989.

12 DINIZ, I. P. Caracterização tecnológica do polvilho azedo produzido em diferentes regiões do estado de Minas Gerais. Viçosa, 2006. 103 p. Tese (Mestrado em Ciência e Tecnologia de Alimentos), Departamento de Tecnologia de Alimentos, Universidade Federal de Viçosa.

13 FERREIRA, A.C.P.; BRAZACA, S.G.C.; ARTHUR, V. Alterações químicas e nutricionais do grão-de-bico (Cicer arietinum L.) cru irradiado e submetido à cocção. Ciência e Tecnologia de Alimentos, Campinas, v. 26 , n. 1, p. $80-88,2006$.

14 FREITAS, M.C.J.; TAVARES, D.Q. Caracterização do grânulo de amido de bananas (AAA-nanicão e AABterra) musa musa. Ciência e Tecnologia de Alimentos, Campinas, v. 25, n. 2, p. 217-222, 2005.

15 HOOVER, R.; RATNAYAKE, W.S. Starch characteristics of black bean, chick pea, lentil, navy bean and pinto bean cultivars grown in Canada. Food Chemistry, v. 78, n. 4, p. 489-498, 2002.

16 HUANG, J. Function-Structure relationships of acetylated pea starches. Wageningen, The Netherlands, 2006. 152 p. Ph.D. thesis (Agrotechnology and Food Sciences). Wageningen University.

17 HUANG, J.; SCHOLS, H.A.; VAN SOEST, J.J.G.; JIN, Z.; SULMANN, E.; VORAGEN, A.G.J. Physicochemical properties and amylopectin chain profiles of cowpea, chickpea and yellow pea starches. Food Chemistry, v. 101, p. 1338-1345, 2007a.

18 HUANG, M.; KENNEDY, J.F.; LI, B.; XU, X.; XIE, B.J. Characters of rice starch gel modified by gellan, carrageenan, and glucomannan: a texture profile analysis study. Carbohydrate Polymers, v. 69, n. 3, p. 411-418, 2007b.

19 JENKINS, P.J.; DONALD, A.M. Gelatinisation of starch: a combined SAXS/WAXS/DSC and SANS study. Carbohydrate Research, v. 308, n. 1-2, p. 133-147, 1998.

20 KAUR, L.; SINGH, J.; MCCARTHY, O.J.; SINGH, H. Physico-chemical, rheological and structural properties of fractionated potato starches. Journal of Food Engineering, v. 82, n. 3, p. 383-394, 2007.

21 KÖKSEL, H.; SIVRI, D.; SCANLON, M.G.; BUSHUK, W. Comparison of physical properties of raw and roasted chickpeas (leblebi). Food research International, v. 31, n. 9, p. 659-665, 1998.

22 LEACH, H.W.; McCOWEN, L.D.; SCHOCH, T.J. Structure of starch granule. I. Swelling and solubility patterns of various starches. Cereal Chemistry, v. 36, n. 6, p. 534-544, 1959. 
23 LEONEL, M. Análise da forma e tamanho de grânulos de amidos de diferentes fontes botânicas. Ciência e Tecnologia de Alimentos, Campinas, v. 27, n. 3, p. 579-588, jul.-set. 2007

24 LEONEL, M.; SARMENTO, S.B.S.; CEREDA, M.P.; GUERREIRO, L.M.R. Extração e caracterização do amido de biri (Canna edulis). Brazilian Journal of Food Technology, v. 5, p. 27-32, 2002.

25 LEONEL, M.; SARMENTO, S.B.S.; CEREDA, M.P.; CÂMARA, F.L.A. Extração e caracterização de amido de jacatupé (Pachyrhizus ahipa). Ciência e Tecnologia de Alimentos, Campinas, v. 23, n. 3, p. 362-365, 2003.

26 MATSUGUMA, L. S. Caracterização do amido de mandioquinha salsa (Arracacia xanthorrhiza) nativo e modificado por oxidação. Ponta Grossa, 2006. 112 p. Tese (Mestrado em Ciência e Tecnologia de Alimentos), Universidade Estadual de Ponta Grossa.

27 MOORTHY, S. N. Tuber crop starches. $2^{\text {nd }}$ ed. Thiruvananthapuram: Central Tuber Crops Research Institute, 2001. $52 \mathrm{p}$.

28 OLIVEIRA, L.B.; RIBEIRO, M.R.; FERRAZ, F.B.; FERREIRA, M.G.V.X.; MERMUT, A.R. Mineralogia, micromorfologia e gênese de solos planossólicos do Sertão do Araripe, estado de Pernambuco. Revista Brasileira de Ciência do Solo, Viçosa, v. 28, n. 4, p. 665-678, ago. 2004.

29 PERONI, F.H.G. Características estruturais e físico-químicas de amidos obtidos de diferentes fontes botânicas. São José do Rio Preto, 2003. 135 p. Tese (Mestrado em Engenharia e Ciência de Alimentos), Universidade Estadual Paulista "Júlio de Mesquita Filho".

30 RATNAYAKE, W.S.; HOOVER, R.; SHAHIDI, F.; PERERA, C.; JANE, J. Composition, molecular structure, and physicochemical properties of starches from four field pea (Pisum sativum L.) cultivars. Food Chemistry, v. 74, n. 2, p. 189-202, 2001.

31 REGE, A.; PAI, J.S. Thermal and freeze-thaw properties of starch of chickpea (Cicer arietinum). Food Chemistry, v. 57, n. 4 , p. 545-547, 1996.

32 RURAL NEWS. Grãos e Cereais. Conheça o cultivo do Grão-de-bico, planta cultivada no cerrado e no sul do Brasil. Disponível em: http://www.zoonews.com.br/noticias2/noticia.php?idnoticia=42747. Acesso em :19 nov. 2005.

33 SALGADO, S.M.; GUERRA, N.B.; ANDRADE, S. A. C.; LIVERA, A.V.S. Caracterização físico-química do grânulo do amido do feijão Caupi. Ciência e Tecnologia de Alimentos, Campinas, v. 25, n. 3, p. 525-530, 2005.

34 SANDHU, K.S.; SINGH, N. Some properties of corn starches II: Physicochemical, gelatinization, retrogradation, pasting and gel textural properties. Food Chemistry, v. 101, n. 4, p. 1499-1507, 2007.

35 SANDHYA RANI, M.R.; BHATTACHARAYA, K.R. Rheology of rice-flour pastes: effect of variety, concentration, and temperature and time of cooking. Journal of Texture Studies, v. 20, n. 2, p. 127137, 1989.

36 SÃO PAULO. Comissão Nacional de Normas e Padrões para Alimentos. Resolução no 12, de 1978. Normas técnicas especiais do Estado de São Paulo relativas a alimentos (e bebidas). Diário Oficial [da] República Federativa do Brasil, Brasília, 24/07/1978. Disponível em: http://anvisa.gov.br/legis/resol/ 12_78.pdf. Acesso em: 02 de março de 2008.

37 SILVA, G.O.; TAKIZAWA, F.F.; PEDROSO, R.A.; FRANCO, C.M.L.; LEONEL, M.; SARMENTO, S.B.S.; DEMIATE, I.M. Características físico-químicas de amidos modificados de grau alimentício comercializados no Brasil. Ciência e Tecnologia de Alimentos, Campinas, v. 26, n. 1, p. 188-197, 2006.

38 SINGH, N.; SANDHU, K.S.; KAUR, M. Characterization of starches separated from Indian chickpea (Cicer arietinum L.) cultivars. Journal of Food Engineering, v. 63, n. 4, p. 441-449, 2004.

39 TEIXEIRA, M.A.V.; CIACCO, C.F.; TAVARES, D.Q.; BONEZZI, A.N. Ocorrência e caracterização do amido resistente em amidos de milho e de banana. Ciência e Tecnologia de Alimentos, Campinas, v. 18, n. 2 , p. 246-246, 1998.

40 VIGNEAU, E.; LOISEL, C.; DEVAUX, M.F.; CANTONI, P. Number of particles for the determination of size distribution from microscopic images. Powder Technology, v. 107, n. 3, p. 243-250, Feb. 2000. 
41 VILPOUX, O.; CEREDA, M.P. Caracterização das fecularias no Brasil. Botucatu: Centro de Raízes Tropicais/UNESP, 1995. 58 p. 